\title{
FUZZY APPROACH FOR GROUP DECISION-MAKING IN CRISIS SITUATIONS
}

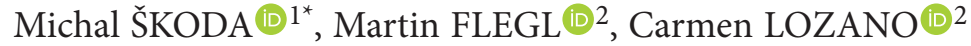 \\ ${ }^{1}$ Faculty of Economics and Management, Czech University of Life Sciences, Prague, Czech Republic \\ ${ }^{2}$ Facultad de Negocios, Universidad La Salle México, Mexico City, Mexico
}

Received 21 February 2020; accepted 24 February 2021

\begin{abstract}
The importance of correct and clear decisions during a complex and difficult situation is very easy to understand, but not so easy to achieve. Especially in situations where decision-makers must decide under time pressure and uncertainty. For instance, typical crisis situations have such characteristics. Given the uncertainty, subjectivity and ambiguity of human knowledge, crisis situations are also characterized by conflicting interests. In this article, we propose an approach based on fuzzy set theory to help decision-makers to find the collective decision considering weights of each member of the decision-making group. More specifically, the proposed approach uses new and innovative transformation of fuzzy numbers through $\alpha$-level cuts. The key role in the transformation process is played by the shape and position of fuzzy numbers. Additionally, the Hamming distance will be used for the final interpretation of the results, in order to minimize the loss of information caused by defuzzification.
\end{abstract}

Keywords: $\alpha$-level, group decision-making, fuzzy number, Hamming distance, linguistic scale, crisis.

JEL Classification: C02, D74, D81, H12.

\section{Introduction}

Decision-making under the uncertainty, subjectivity and ambiguity of human knowledge is specific especially to upper levels of management. One of the situations that is typical for the high level of uncertainty is crisis situation. There is no universally accepted definition of a crisis (Coombs \& Holladay, 2012). However, according to Boin et al. (2005), crisis situations can be defined by three key elements: a threat to a community, uncertainty about the nature of the crisis and an urgent need to respond. For purposes of this article, crisis situation is understood according to Rosenthal et al. (1989, p. 10) as: "A serious threat to the basic structures or the fundamental values and norms of a social system, which under time pressure and highly uncertain circumstances necessitates making critical decisions".

The management and resolution of a crisis is one of the most difficult strategic issues decision makers face because of conditions of high uncertainty, time pressure, and limited control (Burnett, 1998). Crises require coordination between multiple organizations as response capacities and responsibilities are usually not centralized (Ansell et al., 2010). During a crisis, there is generally a common agreement to tackle the crisis. However, a problem arises to reach the unanimity among the participants (Hart et al., 1991), as there are conflicting interests regarding preferred allocation of power and resources (Granot, 1997). This conflict is usually related to questions over certain tasks, domains and jurisdictions (Moynihan, 2009), because participants may have different views over a degree of the threat, nature of the crisis, over the priorities, or basically understand differently the situation, which results in lower level of collaboration (Berlin \& Carlström, 2011; Danielsson, 2016; Kalkman et al., 2018).

The choice of the evaluation approach under uncertainty depends on the type of available data and the kind of the problem (Medasani et al., 1998). It has been inferred that good decision-making model must be able to function in unstructured problems and must tolerate vagueness, ambiguity or inaccurate data (Yu, 2002; Lumbroso \& Vinet, 2012). To minimize errors and risk related to the complexity of crises, methods based on multi-criteria decision analysis are extensively used in such situations (Kailiponi, 2010; Kolen et al., 2013; Zhu et al., 2018). However, the existence of subjectivity in the decision-making can cause difficulties in results predictions, as slight variation in evaluations can greatly affect the final decision

*Corresponding author. E-mail: mskoda@pef.czu.cz

Copyright $\odot 2021$ The Author(s). Published by Vilnius Gediminas Technical University

This is an Open Access article distributed under the terms of the Creative Commons Attribution License (http://creativecommons.org/licenses/by/4.0/), which permits unrestricted use, distribution, and reproduction in any medium, provided the original author and source are credited. 
(Lumbroso \& Vinet, 2012). Fuzzy Theory is very helpful to deal with the vagueness of human thoughts in making decisions (Zadeh, 1965; Lin \& Wu, 2008), as well as to combine human-oriented interpretation together with quantitative and qualitative information (Jia et al., 2016). The theory assumes that people do not think in exact values (yes or no, 1 or 0 , i.e. Boolean logic), but rather distinguish a range of "blurry" values (absolutely, rather yes, maybe no, i.e. linguistic expression) (Buckley et al., 2006; Herrera et al., 2009). Therefore, fuzzy logic provides a simple method to reach a definite conclusion based on vague, ambiguous, imprecise or missing information. This is especially useful way to assess risk levels in cases where experts (participants) do not have enough reliable data (Iliadis, 2005; Jiang et al., 2009; Doskočil, 2015). The use of fuzzy sets in Crisis management is not a rare approach. Many authors, such as Nokhbatolfoghahaayee et al. (2010), Jia et al. (2016) and Drakaki et al. (2018) already applied the fuzzy approach in crisis decision-making in several distinctive areas. The approach presented in this article, unlike others, is enriched by the new way of using $\alpha$-level cuts to transform triangular fuzzy number to trapezoidal fuzzy number. This is in contrast to the typical way of using $\alpha$-level cuts to easily find the membership degree, define total ordering, etc.

Quality of a decision-making process depends primarily on the nature of the problem, the context, and mostly on the decision makers' expertise in the problem area (Wang et al., 2013). In group decision-making problems, it is almost impossible to have a homogeneous group of decision makers whose experiences, knowledge and attitudes are the same or similar. Therefore, it is required to determine the weights of decision makers to reflect their relative importance or contribution to the problem (Cabrerizo et al., 2013; Koksalmis \& Kabak, 2019). These weights can be assigned subjectively based on experts' experience, status or age, or by application of quantitative methods based on available data (Saaty, 1990; Ishizaka \& Nemery, 2013). The advantage of quantitative methods lays in a reduction of the subjectivity. The calculation of weights depends mainly on each situation and its complexity. Ignoring the relative weights of experts can lead to erroneous and incorrect results that cannot be compensated in the final solutions (Mianabadi \& Afshar, 2008). Therefore, it is crucial to specify hierarchical level of members of decision-making group to avoid problems as jurisdictions etc. (Moynihan, 2009). Application of fuzzy theory and a-level cuts enable considering the weights of a decisionmakers within a decision-making group, which creates an opportunity to incorporate different power of votes into the group decision-making process.

The objective of the article is to present a new approach for group decision-making in crisis situations based on innovative transformation of fuzzy numbers. Our ambition in this article is that the presented methodology will be easily understood by an expert with only basic knowledge of fuzzy set theory. Therefore, only the triangular and trapezoidal fuzzy numbers will be used, and the arithmetic operations defined on them will be presented in a simple way without excessive use of mathematical severity.

The remaining of this article has been organized as follows: The second chapter describes the used tools and methods with the main focus on fuzzy mathematics and the whole approach is described in detail. The third chapter provides the case study from crisis management. The fourth chapter provides discussion, where the strengths and weaknesses and other research possibilities are discussed. In the conclusion, the proposed approach and results are summarized.

\section{Materials and methods}

\subsection{Fuzzy logic}

Fuzzy logic or fuzzy set theory provides a means of handling the vagueness inherent in natural language through the use of linguistic variables and quantifiers. Linguistic variables can represent words such as tall, age, hard and beauty. In addition, linguistic quantifiers such as old, many, some, less than, or average are quantifiers as fuzzy subsets, which correspond to imprecise values of an amount (Megahed \& Hassan, 2000).

Fuzzy numbers are a special case of fuzzy sets. A fuzzy set is called fuzzy number if it is convex and normal (Nahmias, 1978).

\subsection{Fuzzy numbers and $\alpha$-level cuts}

The proposed approach is based on the transformation of fuzzy numbers, more specifically on transformation of triangular fuzzy numbers to trapezoidal fuzzy numbers.

\section{Triangular fuzzy number}

A fuzzy number $\mathrm{A}$ is a triangular fuzzy number, if its membership function $\mu_{A}: \mathbb{R} \rightarrow[0,1]$ has the following form

$$
\mu_{A}(x)=\left\{\begin{array}{l}
0 \text { if } x<a_{1} \\
\frac{x-a_{1}}{a_{2}-a_{1}} \text { if } a_{1} \leq x<a_{2} \\
\frac{a_{3}-x}{a_{3}-a_{2}} \text { if } a_{2}<x \leq a_{3} \\
0 \text { if } x>a_{3},
\end{array},\right.
$$

where $a_{1}, a_{2}, a_{3}$ are real numbers and $a_{1} \leq a_{2} \leq a_{3}$. Let us denote a triangular fuzzy number by $A=\left(a_{1}, a_{2}, a_{3}\right)$.

\section{The shape and position of triangular fuzzy number}

The shape of the triangular fuzzy number is one of important variables that reflect the degree of influence of a member of decision-making group on the final decision. In suggested approach a specific triangular fuzzy number where $a_{1}=a_{2}$ or $a_{2}=a_{3}$ will be used. This means that 
the left or right side of the fuzzy number from $a_{2}$ will be ignored.

The position of the fuzzy number is also crucial to the resulting values. The further the fuzzy number is from the origin, the bigger the resulting value will be (Figure 1).

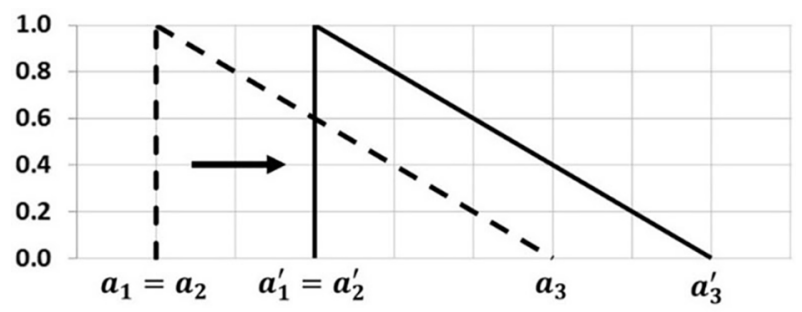

Figure 1. Triangular fuzzy number $A=\left(a_{1}, a_{2}, a_{3}\right)$ is lower than $A=\left(a_{1}^{\prime}, a_{2}^{\prime}, a_{3}^{\prime}\right)$

\section{Trapezoidal fuzzy numbers}

The trapezoidal fuzzy number is determined by four parameters $a_{1} \leq a_{2} \leq a_{3} \leq a_{4}$ and is characterized by membership function $\mu_{A}: \mathbb{R} \rightarrow[0,1]$ in the form of a trapezoid. For the membership function $\mu_{A}$ applies (Klir \& Yuan, 1995):

$$
\mu_{A}(x)=\left\{\begin{array}{r}
0 \text { if } x<a_{1} \\
\frac{x-a_{1}}{a_{2}-a_{1}} \text { if } a_{1} \leq x<a_{2} \\
1 \text { if } a_{2} \leq x \leq a_{3} \\
\frac{a_{4}-x}{a_{4}-a_{3}} \text { if } a_{3}<x \leq a_{4} \\
0 \text { if } x>a_{4} .
\end{array} .\right.
$$

In the following, we use the notation $A=\left(a_{1}, a_{2}, a_{3}, a_{4}\right)$ for trapezoidal fuzzy number.

\section{Arithmetic operations on fuzzy numbers}

The arithmetic operations on trapezoidal fuzzy numbers are established in the following way. Let $A=\left(a_{1}, a_{2}, a_{3}, a_{4}\right)$ and $B=\left(b_{1}, b_{2}, b_{3}, b_{4}\right)$ be two trapezoidal fuzzy numbers and $\mathrm{k}$ a real number. Then, the sum and product are given by

$$
\begin{aligned}
& A+B=\left(a_{1}+b_{1}, a_{2}+b_{2}, a_{3}+b_{3}, a_{4}+b_{4}\right), \\
& k \times A=\left(k a_{1}, k a_{2}, k a_{3}, k a_{4}\right) .
\end{aligned}
$$

It is easy to see that the sum of two trapezoidal fuzzy numbers, is also a trapezoidal fuzzy number.

The average for $n$ trapezoidal fuzzy numbers $\left(a_{j}, b_{j}, c_{j}, d_{j}\right), j=1, \ldots, n$ is the following:

$$
A_{\text {avg }}=\left(\frac{1}{n} \sum_{i=1}^{n} a_{i}, \frac{1}{n} \sum_{i=1}^{n} b_{i}, \frac{1}{n} \sum_{i=1}^{n} c_{i}, \frac{1}{n} \sum_{i=1}^{n} d_{i}\right) .
$$

This operation yields trapezoidal fuzzy numbers as a result (Bojadziev \& Bojadziev, 2007, p. 68).

\section{Transformation of triangular fuzzy number to trapezoidal fuzzy number}

Suppose we have a triangular fuzzy number and a real number $\alpha \in[0,1]$ that will arise from influence of a specific member in the decision-making group. The new trapezoidal fuzzy number, which kernel is equal to the $\alpha$-cut of original triangular fuzzy number, will be called the transformed fuzzy number.

Definition: The transformation of triangular fuzzy number $A=\left(a_{1}, a_{2}, a_{3}\right)$ is a trapezoidal fuzzy number $A_{\alpha}=\left(a_{1}, a_{2 \alpha}, a_{3 \alpha}, a_{4}\right)$, where the element $a_{1}$ remain the same and element $a_{3}$ from the original triangular fuzzy number will become element $a_{4}$ of the transformed trapezoidal fuzzy number, in other words $a_{4}:=a_{3}$. New values of $a_{2 \alpha}$ and $a_{3 \alpha}$ are calculated using the following formulas:

$$
\begin{aligned}
& a_{2 \alpha}=a_{1}+\alpha \times\left(a_{2}-a_{1}\right) ; \\
& a_{3 \alpha}=a_{3}-\alpha \times\left(a_{3}-a_{2}\right) .
\end{aligned}
$$

Then the new fuzzy number will be:

$$
\begin{aligned}
& A_{\alpha}=\left(a_{1}, a_{2 \alpha}, a_{3 \alpha}, a_{4}\right)= \\
& \left(a_{1}, a_{1}+\alpha \times\left(a_{2}-a_{1}\right), a_{3}-\alpha \times\left(a_{3}-a_{2}\right), a_{3}\right) .
\end{aligned}
$$

The lower the $\alpha$ is, the greater the influence of a specific member of the decision-making group on the decision will be. Graphical representation of this transformation is shown in the Figure 2. Also, in order to achieve the biggest effect of transformation, the $a_{1}$ and $a_{2}$ or $a_{2}$ and $a_{3}$ will always be the same (as mentioned in chapter The Shape and Position of Triangular Fuzzy Number). In other words, the smaller the difference between outcoming value of $a_{2}-a_{1}$ and $a_{3}-a_{2}$, the smaller the transformation effect and the influence of a specific member of the decision-making group on the decision will be.

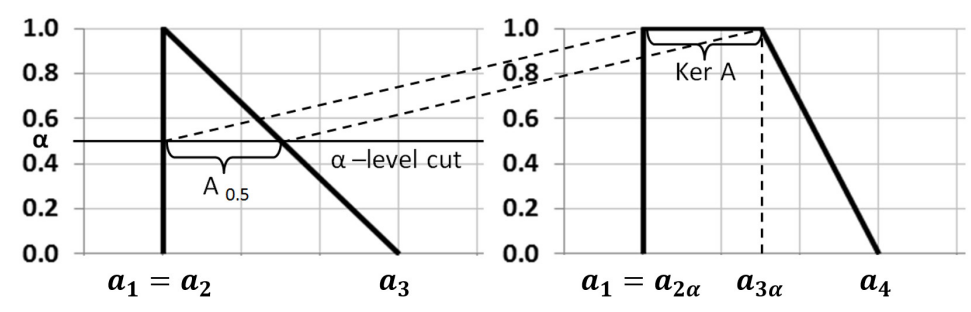

Figure 2. Transformation of triangular to trapezoidal fuzzy number 


\subsection{Fuzzy linguistic scale}

For the purposes of expression of an agreement level, a linguistic fuzzy scale will be used. There are many different linguistic scales described for example in Lubiano et al. (2016), Ryjov (2003) or Xu (2012). In this article, the Likert scale will be used. A linguistic variable is defined using a quintuple $(X, T, U, G, M)$ where $X$ is the name of the variable, $T=\left\{T_{1}, T_{2}, \ldots, T_{n}\right\}$ is the set of terms of $X, U$ is the universe of discourse (generally $[0,1]$ ), $G$ is a syntactic rule for generating the derived terms, and $M$ is a semantic rule for associating each term with proper fuzzy set (number) defined on $U$ (Zhang et al., 2005). Conventional values of cardinality used in the linguistic models are 5 or 7 , where the midterm represents an assessment of "approximately 0.5 ", and with the rest of the terms being placed symmetrically around it (Carrasco et al., 2011). Table 1 illustrates an example of a fuzzy linguistic scale.

Table 1. Fuzzy linguistic scale

\begin{tabular}{|c|l|c|}
\hline$T_{j}$ & Linguistic Term & $\begin{array}{c}\text { Fuzzy Number } \\
M\left(T_{j}\right)=\left(t_{1 j}, t_{2 j}, t_{3 j}, t_{4 j}\right)\end{array}$ \\
\hline$T_{1}$ & Strongly Agree & $(0,0,0,0)$ \\
\hline$T_{2}$ & Agree & $(0.15,0.15,0.20,0.40)$ \\
\hline$T_{3}$ & Do not know & $(0.30,0.30,0.35,0.60)$ \\
\hline$T_{4}$ & Disagree & $(0.45,0.45,0.50,0.80)$ \\
\hline$T_{5}$ & Strongly Disagree & $(0.60,0.60,0.65,1)$ \\
\hline
\end{tabular}

\subsection{Defuzzification}

The goal of defuzzification is to interpret the fuzzy number as proper crisp value to be used by the decision-maker (Sechilariu \& Locment, 2016). There exist many defuzzification methods, but the center of gravity (COG) is often preferred among them (Užga-Rebrovs \& Kulıešova, 2017). This method returns the value of the center of area under the curve created by the membership functions (Masoum \& Fuchs, 2015).

Specifically, if we suppose $A$ is a trapezoidal fuzzy number, for the COG of trapezoidal fuzzy number $A$, the following applies (Wang et al., 2006):

$$
\operatorname{COG}(A)=\frac{1}{3} \times \frac{a_{4}^{2}+a_{3}^{2}-a_{2}^{2}-a_{1}^{2}+a_{4} a_{3}-a_{2} a_{1}}{a_{4}+a_{3}-a_{2}-a_{1}},
$$

where $\operatorname{COG}(A)$ is the center of gravity of the trapezoidal fuzzy number $A$ that is defined by four elements $A=\left(a_{1}, a_{2}, a_{3}, a_{4}\right)$.

\subsection{Hamming distance}

The linguistic term expressing the result of voting $A=\left(a_{1}, a_{2}, a_{3}, a_{4}\right)$ is received using method for determination of distance between numbers. The Hamming distance for trapezoidal fuzzy numbers is defined as follows (Shallit, 2009). Given $A=\left(a_{1}, a_{2}, a_{3}, a_{4}\right)$ and
$B=\left(b_{1}, b_{2}, b_{3}, b_{4}\right)$ be two trapezoidal fuzzy numbers with membership functions $\mu_{A}$ and $\mu_{B}$, respectively. The Hamming distance is defined as

$$
d_{H}(A, B)=\sum_{j=1}^{n}\left|a_{j}-b_{j}\right| .
$$

The distance coefficient is always between 0 and $+\infty$, where 0 refers to the ideal solution.

\subsection{Process of the decision-making}

In this section, each step of the proposed approach of group decision-making in a crisis situation is described in detail.

Step 1: Selection of members of the decision-making group

The first step of this approach is the selection of members of a decision-making group for crisis situations. As Björck (2016) confirms, there are various crisis types and different points of views. We try to create the most universal decision-making response group inspired by composition of Security Councils of main cities in the Czech Republic as Prague, Ostrava, Pardubice, etc. Also, we took into consideration the fact that groups composed of individuals with different characteristics have the potential to reach better decisions especially in highly uncertain situations, because they access greater variety of information sources than homogeneous groups (Mello \& Ruckes, 2006).

The fictitious decision-making group consists of members presented in Table 2. Chairman manages the meetings and discussions, whereas Deputy Chairman supports the Chairman and in case of his absence takes over his role. The position of Secretary is primarily to ensure formal accuracy and support the Chairman or eventually the Deputy Chairman. The rest of members has no special duties or rights regarding the organization.

Table 2. Typical members of decision-making group

\begin{tabular}{|c|l|l|}
\hline No. & \multicolumn{1}{|c|}{ Position } & \multicolumn{1}{c|}{ Profession / Specialization } \\
\hline 1 & Chairman & Mayor \\
\hline 2 & Deputy Chairman & Deputy Mayor \\
\hline 3 & Secretary & Head of Crisis Management \\
\hline 4 & Member & Representative of Police \\
\hline 5 & Member & Representative of Fire Brigade (FB) \\
\hline 6 & Member & $\begin{array}{l}\text { Representative of Emergency } \\
\text { Medical Service (EMS) }\end{array}$ \\
\hline 7 & Member & Representative of Military \\
\hline
\end{tabular}

Step 2: Determination of criteria

In this step the determination of criteria, by which the weights of a members in the decision-making group will be set, should be done. Saaty and Vargas (1994) propose criteria such as expertise, previous performance, experience or, for example, an effort on the problem. For 
purposes of the Case study, the decision-makers importance in a hierarchy (position in the organizational structure) and relevance in the area of decision-making (specialization and knowledge of the issue) will be used as the criteria to set weights.

\section{Step 3: Selection of fuzzy linguistic scales}

In the third step of this approach, it is necessary to define linguistic scales and related fuzzy numbers. For this purpose, Likert scales are used, asking respondents to indicate their levels of agreement with a declarative statement. The advantage of a Likert scale lies in possibility of its easy construction and modification, plus the measurements based on Likert scaling have demonstrated a good reliability (Li, 2013).

Every model should consist at least three fuzzy linguistic scales. First scale for the voting itself, where the decision-makers express the degree of agreement or disagreement with a proposal. Second scale for considering the weights of each member of decision-making group and the last scale for interpretation of results.

For the purposes of the Case Study, four fuzzy linguistic scales will be used, since we will have two criteria by which the weight of each member of decision-making group will be determined. Unlike in articles of Lyu et al. (2020) or Voskoglou (2018), where the construction of fuzzy linguistic scales is based partly on calculations, the construction of fuzzy linguistic scales in this article, with only one exception, is based on the estimation of an expert in the field of crisis management. All in accordance with the rules about relationship between curve and linguistic statement set out in publication of Chen and Hwang (1992). Specific shape of triangular fuzzy numbers described in chapter Fuzzy Numbers and $\alpha$-level cuts will be used. This ensures that the effect of the fuzzy transformation, described also in chapter Fuzzy Numbers and a-level cuts, on the resulting value after defuzzification will be in the desired direction.

Further, the fuzzy linguistic scale described in Table 3 and Figure 3 will be used to express the level of agreement or disagreement of a decision-maker with a proposal. The values of the triangular fuzzy number where $\mu=1$ will be 0.35 for linguistic term Strongly Disagree, 0.45 for Disagree, 0.55 for Agree and 0.65 for Strongly Agree. In case of negative level of agreement (Strongly Disagree, Disagree) the right side of the fuzzy number will be ignored in order to receive more extreme values in the negative direction after the transformation of the fuzzy number (described in Chapter 1.2.). On the same principle, in case of the positive level of agreement (Strongly Agree, Agree), the left side of the fuzzy number will be ignored.

It should also be noticed that the scale expressing the level of agreement or disagreement with a proposal in the Case Study is a four-part scale without a middle option. As Nowlis et al. (2002) confirm, the use of even-point scales is forcing respondents to choose a position, which is desirable in a crisis situation.
Table 3. Scale expressing level of agreement

\begin{tabular}{|l|l|}
\hline \multicolumn{1}{|c|}{ Linguistic Term } & Fuzzy Number \\
\hline Strongly Agree & $(0.65,0.65,1.0)$ \\
\hline Agree & $(0.55,0.55,0.9)$ \\
\hline Disagree & $(0.1,0.45,0.45)$ \\
\hline Strongly Disagree & $(0.0,0.35,0.35)$ \\
\hline
\end{tabular}

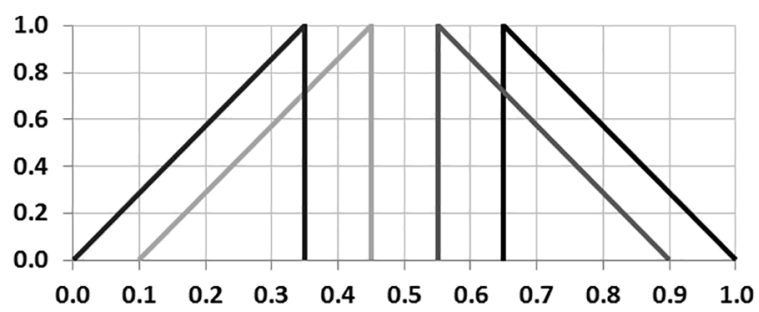

Figure 3. Fuzzy scale expressing level of agreement

The next fuzzy linguistic scales should be used to describe weight of each member of the decision-making group.

In the Case Study, two fuzzy linguistic scales will be used to consider the weights. On the scale described in Table 4 and Figure 4 the importance in the hierarchy of a member within the group will be evaluated. The values of the triangular fuzzy number where $\mu=1$ will be 0.4 for linguistic term Very Important, 0.6 for Important, 0.8 for Moderately Important, 1.0 for Slightly Important and, finally, 1.0 for Not Important. Since the resulting fuzzy number of the scale can be later transformed and the defuzzification of the number will be used as a (as described in the Step 4) the right side of the fuzzy number will be ignored in order to receive lower value of $a$ after each transformation (described in Chapter 1.2.).

Table 4. Scale expressing importance in hierarchy

\begin{tabular}{|l|c|}
\hline \multicolumn{1}{|c|}{ Linguistic Term } & Fuzzy Number \\
\hline Very Important & $(0.0,0.4,0.4)$ \\
\hline Important & $(0.2,0.6,0.6)$ \\
\hline Moderately Important & $(0.4,0.8,0.8)$ \\
\hline Slightly Important & $(0.6,1.0,1.0)$ \\
\hline Not Important & $(1.0,1.0,1.0)$ \\
\hline
\end{tabular}

Evaluation of the relevance of each member in the area of decision-making will be evaluated on the scale described in Table 5 and Figure 4. The fuzzy linguistic scale is identical with the previous one except that it uses different linguistic terms.

Finally, the fuzzy linguistic scale used for the interpretation of the result should be based on the two extreme fuzzy numbers calculated as the most positive and the most negative results of the voting that the model (as described in the Chapter 1.6.) can theoretically allow. For the purposes of Case Study, the scale described in Table 6 and Figure 5 was calculated. 
Table 5. Scale expressing relevance in the area

\begin{tabular}{|l|c|}
\hline \multicolumn{1}{|c|}{ Linguistic Term } & Fuzzy Number \\
\hline Very Relevant & $(0.0,0.4,0.4)$ \\
\hline Relevant & $(0.2,0.6,0.6)$ \\
\hline Moderately relevant & $(0.4,0.8,0.8)$ \\
\hline Slightly Relevant & $(0.6,1.0,1.0)$ \\
\hline Not Relevant & $(1.0,1.0,1.0)$ \\
\hline
\end{tabular}

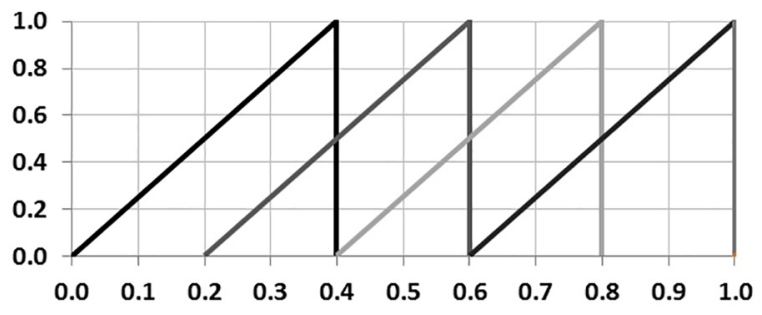

Figure 4. Fuzzy scale expressing importance in hierarchy and the relevance in the area

Table 6. Scale with possible results

\begin{tabular}{|l|c|}
\hline \multicolumn{1}{|c|}{ Linguistic Term } & Fuzzy Number \\
\hline Accept & $(0.65,0.65,0.92,1.00)$ \\
\hline Reject & $(0.00,0.08,0.35,0.35)$ \\
\hline
\end{tabular}

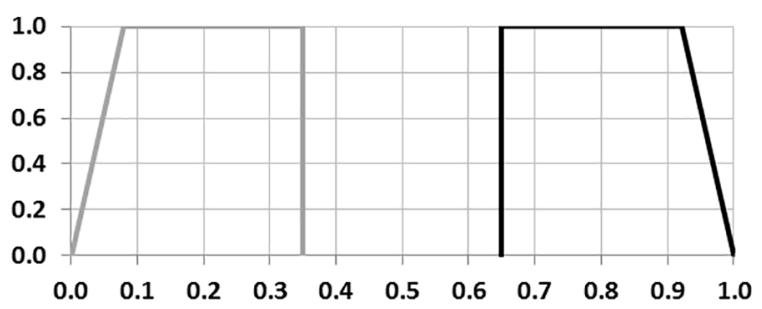

Figure 5. Fuzzy scale with possible results

Step 4: Determination of weight of each member of the decision-making group

In this step, the weight of each member in the decision-making group is determined based on pre-selected criteria (as, for example, level of knowledge, seniority or area of interest). The weight of a member is represented by value $\alpha$. Based on the size of $\alpha$, the transformation of fuzzy number representing the vote of the member will be done later. The $\alpha$ for each member results from defuzzification of a fuzzy number $A$ selected on the prearranged fuzzy linguistic scale.

In case that there is more than one criterion for the determination of weight, the order of criteria needs to be established. Then, the a obtained from the defuzzification of the first fuzzy number, which is resulting from the evaluation according to the first criterion, will be used to transform the second fuzzy number, which is resulting from the evaluation according to the second criterion, etc.
The last criterion provides the final a representing the final weight of a member.

Step 5: Voting of individual members of the decisionmaking group

In the fifth step, which is also the only one that takes place after a crisis situation occurs, each member of the decision-making group votes on the pre-defined fuzzy linguistic scale to express the level of agreement or disagreement with the proposal. If the decision-maker's weight is $\alpha<1$, then the transformation of the fuzzy number resulting from the decision-maker's vote should be done (see Formula 8). Then, based on the resulting fuzzy number of each member of the decision-making group, the overall average fuzzy number should be calculated (see Formula 5). After that, based on the Hamming distance approach, the difference between the resulting average fuzzy number and the fuzzy numbers in the fuzzy linguistic scale used for the final interpretation of results should be calculated. The final result of the voting (e.g. Yes or No, Accept or Reject) should be selected based on the shortest Hamming distance of a fuzzy number from the fuzzy linguistic scale to the average fuzzy number.

\section{Case study}

The goal of the Case Study is to decide whether to accept or reject a possible crisis decision in a predetermined scenario. Since the voting in the Security Councils or other crisis institutions in the Czech Republic is rare and the votes of individual members are usually identical or unlisted, we have decided that for the clarity of this Case Study the designed approach will be applied on a fictitious crisis scenario and the votes of members of decisionmaking group will be generated randomly. The fictitious crisis scenario created by an expert in the area of crisis management is as follows:

There is a rapidly spreading mass infection in the capital city of Prague. Approximately $10 \%$ of the population is infected and the hospital reports first deaths. The infection is manifested by severe fevers and vomiting. The type or source of infection is not yet known. It is necessary to decide on quarantine (in order to limit the spread of the infection) for the whole area of Prague.

Weights of each member of the decision-making group, represented by $\alpha$, were calculated based on evaluation of importance in the hierarchy within the decisionmaking group, as well as based on relevance in the area of decision-making. All done in cooperation with an expert in crisis management.

The initial (first) weight, which reflects the importance of a member, was assigned to each member by selecting the most appropriate linguistic term on the fuzzy linguistic scale presented in Table 4 . The corresponding fuzzy number to the term was defuzzified and thus the first value $\alpha$ was obtained specifically for each member. Calculations can be seen in the Table 7 . 
The final weights of each member were gained by selecting the most appropriate linguistic term (representing importance - second criterion) for each member on the fuzzy linguistic scale presented in Table 5 . The corresponding fuzzy number to the selected linguistic term was transformed (as described in Chapter 1.2.) using the initial weight as $\alpha$ level. The transformed fuzzy number was defuzzified and the result used as the final weight specific for each member, as shown in Table 8 .
Votes, more precisely the level of agreement or disagreement with declaration of quarantine of each member, were generated randomly by using a generator of random numbers. In Table 9 the individual votes of each member can be found along with corresponding triangular fuzzy number and its transformation (as described in Chapter 1.2.) by respective $\alpha$ (final weight of individual members). The average fuzzy number (final vote) resulting from individual votes of each member of decision-making group is also presented in Table 9.

Table 7. Members of the decision-making group with assigned weights related to importance in hierarchy

\begin{tabular}{|c|c|c|c|c|}
\hline \multirow[b]{2}{*}{ Position } & \multirow[b]{2}{*}{ Profession / Specialization } & \multicolumn{3}{|c|}{ Calculation of Initial Weight } \\
\hline & & Importance & $\begin{array}{c}\text { Triangular } \\
\text { Fuzzy Number }\end{array}$ & $\begin{array}{l}\text { Defuzzification - } \\
\text { Initial Weight }(\alpha)\end{array}$ \\
\hline Chairman & Mayor & Very Important & $(0.0,0.4,0.4)$ & 0.267 \\
\hline Deputy Chairman & Deputy Mayor & Important & $(0.2,0.6,0.6)$ & 0.467 \\
\hline Secretary & Head of Crisis Management & Important & $(0.2,0.6,0.6)$ & 0.467 \\
\hline Member & Representative of Police & Moderately Important & $(0.4,0.8,0.8)$ & 0.667 \\
\hline Member & Representative of FB & Moderately Important & $(0.4,0.8,0.8)$ & 0.667 \\
\hline Member & Representative of EMS & Moderately Important & $(0.4,0.8,0.8)$ & 0.667 \\
\hline Member & Representative of Military & Moderately Important & $(0.4,0.8,0.8)$ & 0.667 \\
\hline
\end{tabular}

Table 8. Members of the decision-making group with assigned final weights

\begin{tabular}{|l|l|l|c|c|c|}
\hline \multirow{3}{*}{ Position } & \multicolumn{2}{c|}{$\begin{array}{c}\text { Profession / } \\
\text { Specialization }\end{array}$} & \multicolumn{1}{c|}{ Calculation of Final Weight } \\
\cline { 3 - 7 } & & \multicolumn{1}{c|}{ Relevance } & $\begin{array}{c}\text { Triangular } \\
\text { Fuzzy Number }\end{array}$ & $\begin{array}{c}\text { Transformed } \\
\text { Fuzzy Number }\end{array}$ & $\begin{array}{c}\text { Defuzzification - } \\
\text { Final Weight }(\alpha)\end{array}$ \\
\hline Chairman & Mayor & Slightly Relevant & $(0.6,1.0,1.0)$ & $(0.6,0.70,1.0,1.0)$ & 0.825 \\
\hline Dep. Chairman & Deputy Mayor & Slightly Relevant & $(0.6,1.0,1.0)$ & $(0.6,0.79,1.0,1.0)$ & 0.842 \\
\hline Secretary & Head of Crisis Mgmt. & Moderately Relevant & $(0.4,0.8,0.8)$ & $(0.4,0.59,0.8,0.8)$ & 0.642 \\
\hline Member & Representative of Police & Moderately Relevant & $(0.4,0.8,0.8)$ & $(0.4,0.67,0.8,0.8)$ & 0.656 \\
\hline Member & Representative of FB & Relevant & $(0.2,0.6,0.6)$ & $(0.2,0.47,0.6,0.6)$ & 0.456 \\
\hline Member & Representative of EMS & Very Relevant & $(0.0,0.4,0.4)$ & $(0.0,0.27,0.4,0.4)$ & 0.256 \\
\hline Member & Representative of Military & Slightly Relevant & $(0.6,1.0,1.0)$ & $(0.6,0.87,1.0,1.0)$ & 0.856 \\
\hline
\end{tabular}

Table 9. Individual votes of members and resulting average fuzzy number

\begin{tabular}{|l|l|l|l|l|}
\hline \multirow{2}{*}{\multicolumn{1}{c|}{ Position }} & \multirow{2}{*}{ Profession / Specialization } & \multicolumn{3}{c|}{ Calculation of Weighted Vote } \\
\cline { 3 - 5 } & & \multicolumn{1}{|c|}{ Vote } & $\begin{array}{c}\text { Triangular } \\
\text { Fuzzy Number }\end{array}$ & $\begin{array}{c}\text { Transformed } \\
\text { Fuzzy Number }\end{array}$ \\
\hline Chairman & Mayor & Strongly Disagree & $(0.00,0.35,0.35,0.35)$ & $(0.00,0.29,0.35,0.35)$ \\
\hline Deputy Chairman & Deputy Mayor & Strongly Agree & $(0.65,0.65,0.65,1.00)$ & $(0.65,0.65,0.71,1.00)$ \\
\hline Secretary & Head of Crisis Management & Disagree & $(0.10,0.45,0.45,0.45)$ & $(0.10,0.32,0.45,0.45)$ \\
\hline Member & Representative of Police & Agree & $(0.55,0.55,0.55,0.90)$ & $(0.55,0.55,0.67,0.90)$ \\
\hline Member & Representative of FB & Disagree & $(0.10,0.45,0.45,0.45)$ & $(0.10,0.26,0.45,0.45)$ \\
\hline Member & Representative of EMS & Disagree & $(0.10,0.45,0.45,0.45)$ & $(0.10,0.19,0.45,0.45)$ \\
\hline Member & Representative of Military & Strongly Agree & $(0.65,0.65,0.65,1.00)$ & $(0.65,0.65,0.70,1.00)$ \\
\hline & & Average Fuzzy Number - Final Vote & $(0.31,0.42,0.54,0.66)$ \\
\hline
\end{tabular}


Table 10. Hamming distance for each result of the recruiting process

\begin{tabular}{|l|c|}
\hline \multicolumn{1}{|c|}{ Variant of the Result } & Hamming Distance \\
\hline Accept & 1.301 \\
\hline Reject & 1.141 \\
\hline
\end{tabular}

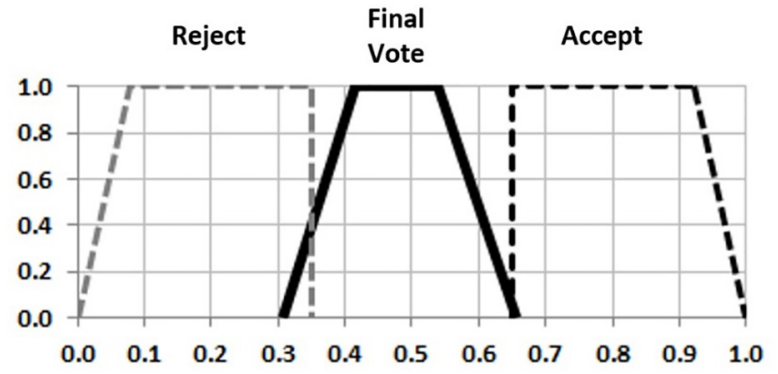

Figure 6. Resulting average fuzzy number (solid line) and possible results (dot lines)

The minimal Hamming distance of the average fuzzy number (that represents the final vote), and the fuzzy numbers (that represent possible results of the voting) presented on fuzzy linguistic scale described in Table 6 is equal to 1.141. The calculated Hamming distances are presented in Table 10.

Based on the result of voting, the final decision should be to "Reject" the declaration of quarantine for the whole area of Prague. As it is obvious from Table 10 and Figure 6 the result is not unambiguous and even a small change in the degree of agreement of one member could cause a different result of the voting.

\section{Discussion}

\section{Interpretation of results}

Since decision makers during the voting have to choose from multiple categories and are not limited to binary choice (yes / no), the results can be more accurate, as confirmed, for example, by Chen et al. (2017), who said that the greater the number of scale categories is, the more accurate the resulting evaluation will be. Additionally, by interpreting the results using Hamming distance, it is possible to interpret the power with which a proposal was accepted or rejected. In other words, it is possible to determine the degree of agreement or disagreement with a given proposal within the decision-making group, as it is obvious from example in the Case study. In the presented Case study, the final result was to "Reject" the declaration of quarantine with Hamming distance of 1.141. However, the difference of Hamming distances between "Accept" and "Reject" was only 0.16 . This slight difference provides the basis for claiming that the decision was not too strong. In this case, a simple scale could be established to interpret the power with which a proposal was accepted or rejected.

\section{Accuracy of results}

Weights calculated by a certain method are more accurate than the weights obtained by the methods of a direct weight assignment based on the expert's understanding of the significance of criteria (Pamučar et al., 2018). Based on this statement, it would be appropriate to supplement the expert estimate with an assignment method, in order to make the achieved results more accurate. For example, widely accepted Analytical Hierarchy Process (AHP) can be used in this case (Saaty, 1977, 1980), which enable to combine qualitative and quantitative evaluation to express weights.

In addition, the possible weakness regarding accuracy of results can also be found in the setting of the fuzzy linguistic scales. The slope and position of the fuzzy numbers is essential and should be set by an expert or group of experts who should determine what values a specific fuzzy number can reach. Not only within the Case Study the only fuzzy linguistic scale that is predetermined is the scale of possible results (see Table 6), because the Hamming distance of the most important and relevant member in case of "Strongly Agree" or "Strongly Disagree" has to be 0 . The proposed approach would also benefit from testing on many different scenarios. Especially regarding influence of diverse conditions on weights and assessments.

Finally, it is important to note that linear fuzzy numbers do not need to be sufficient in some cases. Sometimes, it may be necessary to use curved or non-linear fuzzy numbers for more accurate results. For example, in case that increase of transformation effect with lowering alpha should be considered.

\section{Hierarchical order of weights}

In case there is more than one criterion determining the weight of a decision-maker and, at the same time, all fuzzy linguistic scales related to the criterion are the same, the following criterion in the hierarchy will always have bigger impact on the final results, than the previous criterion in the hierarchy. As it can be seen in the Case Study, where the fuzzy linguistic scales determining the weight of decision-makers are the same (see Table 7 and 8), the relevance in the area of decision-making of a member has significantly greater impact then the importance in the hierarchy. That is why, the construction of the hierarchical structure must be carefully considered that the most important criteria should be placed last.

\section{Conclusions}

Managerial decision-making often involves the consideration of multiple criteria with high levels of uncertainty (Hodgett \& Siraj, 2019). The presented approach helps us to manage the imprecise ambiguous information. As the case study indicates, the approach provides accurate results while working with vague concepts. The approach with transformation of fuzzy numbers could be also used 
in many areas where it is necessary to consider weights, not only in a group decision-making in crisis. The case study is only a brief example of a specific situation. Practical use of the suggested approach would require greater robustness. For example, the relevance of individual members in the decision-making group should be in a preprepared matrix, with all possible complex situations that may happen. As mentioned in Discussion, in the context of further research, it would be useful to focus on method of determining weights by expert and especially on more precise slope adjustment of fuzzy linguistic scales. Also use of non-linear fuzzy numbers should be considered as well.

\section{Funding}

This work was supported by Internal Grant Agency of the University of Life Sciences Prague under Grant number 20181012.

\section{Author contributions}

MŠ invented the essence of the article and wrote the first draft of the article. MF contribute on design of case study and final adjustments of the article. CL was responsible for mathematical review and related adjustments.

\section{Disclosure statement}

We declare that this manuscript is original, has not been published before and is not currently being considered for publication elsewhere. Moreover, we declare no conflicts of interests associated with this paper.

\section{References}

Ansell, C., Boin, A., \& Keller, A. (2010). Managing transboundary crises: identifying the building blocks of an effective response system. Journal of Contingencies and Crisis Management, 18(4), 195-207.

https://doi.org/10.1111/j.1468-5973.2010.00620.x

Berlin, J. M., \& Carlström, E. D. (2011). Why is collaboration minimised at the accident scene? Disaster Prevention and Management: An International Journal, 20(2), 159-171. https://doi.org/10.1108/09653561111126094

Björck, A. (2016). Crisis typologies revisited: an interdisciplinary approach. Central European Business Review, 5(3), 25-37. https://doi.org/10.18267/j.cebr.156

Boin, A., Hart, P. t, Stern, E., \& Sundelius, B. (2005). The politics of crisis management. Cambridge University Press. https://doi.org/10.1017/CBO9780511490880

Bojadziev, G., \& Bojadziev, M. (2007). Fuzzy logic for business, finance, and management. In Advances in Fuzzy Systems Applications and Theory, 23 (2nd ed.). World Scientific Publishing Company. https://doi.org/10.1142/6451

Buckley, J. J., Eslami, E., \& Feuring, T. (2006). Fuzzy mathematics in economics and engineering. Physica-Verlag Publishing.

Burnett, J. J. (1998). A strategic approach to managing crises. Public Relations Review, 24(4), 475-488.

https://doi.org/10.1016/S0363-8111(99)80112-X
Cabrerizo, F. J., Herrera-Viedma, E., \& Pedrycz, W. (2013). A method based on PSO and granular computing of linguistic information to solve group decision making problems defined in heterogeneous contexts. European Journal of Operational Research, 230(3), 624-633. https://doi.org/10.1016/j.ejor.2013.04.046

Carrasco, R., Villar, P., Hornos, M., \& Herrera-Viedma, E. (2011). A linguistic multi-criteria decision making model applied to the integration of education questionnaires. International Journal of Computational Intelligence Systems, 4(5), 946-959. https://doi.org/10.2991/ijcis.2011.4.5.19

Chen, L., Huang, Y.-C., Bai, R.-Z., \& Chen, A. (2017). Regional disaster risk evaluation of China based on the universal risk model. Natural Hazards, 89(2), 647-660. https://doi.org/10.1007/s11069-017-2984-2

Chen, S., \& Hwang, C. (1992). Fuzzy multiple attribute decision making methods and applications. Springer. https://doi.org/10.1007/978-3-642-46768-4

Coombs, W. T., \& Holladay, S. J. (2012). The handbook of crisis communication. Wiley-Blackwell.

Danielsson, E. (2016). Following routines: a challenge in crosssectorial collaboration. Journal of Contingencies and Crisis Management, 24(1), 36-45.

https://doi.org/10.1111/1468-5973.12093

Doskočil, R. (2015). An evaluation of total project risk based on fuzzy logic. Business: Theory and Practice, 17(1), 23-31. https://doi.org/10.3846/btp.2016.534

Drakaki, M., Gören, H. G., \& Tzionas, P. (2018). An intelligent multi-agent based decision support system for refugee settlement siting. International Journal of Disaster Risk Reduction, 31, 576-588. https://doi.org/10.1016/j.ijdrr.2018.06.013

Granot, H. (1997). Emergency inter-organizational relationships. Disaster Prevention and Management: An International Journal, 6(5), 305-310. https://doi.org/10.1108/09653569710193736

Herrera, F., Alonso, S., Chiclana, F., \& Herrera-Viedma, E. (2009). Computing with words in decision making: foundations, trends and prospects. Fuzzy Optimization and Decision Making, 8(4), 337-364. https://doi.org/10.1007/s10700-009-9065-2

Hodgett, R. E., \& Siraj, S. (2019). SURE: A method for decisionmaking under uncertainty. Expert Systems with Applications, 115, 684-694. https://doi.org/10.1016/j.eswa.2018.08.048

Iliadis, L. (2005). A decision support system applying an integrated fuzzy model for long-term forest fire risk estimation. Environmental Modelling \& Software, 20(5), 613-621. https://doi.org/10.1016/j.envsoft.2004.03.006

Ishizaka, A., \& Nemery, P. (2013). Multi-criteria decision analysis: methods and software. Wiley.

https://doi.org/10.1002/9781118644898

Jia, X., Morel, G., Martell-Flore, H., Hissel, F., \& Batoz, J.-L. (2016). Fuzzy logic based decision support for mass evacuations of cities prone to coastal or river floods. Environmental Modelling \& Software, 85, 1-10. https://doi.org/10.1016/j.envsoft.2016.07.018

Jiang, W., Deng, L., Chen, L., Wu, J., \& Li, J. (2009). Risk assessment and validation of flood disaster based on fuzzy mathematics. Progress in Natural Science, 19(10), 1419-1425. https://doi.org/10.1016/j.pnsc.2008.12.010

Kailiponi, P. (2010). Analyzing evacuation decisions using multi-attribute utility theory (MAUT). Procedia Engineering, 3, 163-174. https://doi.org/10.1016/j.proeng.2010.07.016

Kalkman, J. P., Kerstholt, J. H., \& Roelofs, M. (2018). Crisis response team decision-making as a bureau-political process. Journal of Contingencies and Crisis Management, 26(4), 480490. https://doi.org/10.1111/1468-5973.12243 
Klir, G. J., \& Yuan, B. (2015). Fuzzy sets and fuzzy logic: theory and applications. Pearson.

Koksalmis, E., \& Kabak, Ö. (2019). Deriving decision makers' weights in group decision making: An overview of objective methods. Information Fusion, 49, 146-160. https://doi.org/10.1016/j.inffus.2018.11.009

Kolen, B., Kok, M., Helsloot, I., \& Maaskant, B. (2013). EvacuAid: a probabilistic model to determine the expected loss of life for different mass evacuation strategies during flood threats. Risk Analysis, 33(7), 1312-1333. https://doi.org/10.1111/j.1539-6924.2012.01932.x

Li, Q. (2013). A novel Likert scale based on fuzzy sets theory. Expert Systems with Applications, 40(5), 1609-1618. https://doi.org/10.1016/j.eswa.2012.09.015

Lin, C.-J., \& Wu, W.-W. (2008). A causal analytical method for group decision-making under fuzzy environment. Expert Systems with Applications, 34(1), 205-213. https://doi.org/10.1016/j.eswa.2006.08.012

Lubiano, M. A., Montenegro, M., Sinova, B., de la Rosa de Sáa, S., \& Gil, M. Á. (2016). Hypothesis testing for means in connection with fuzzy rating scale-based data: algorithms and applications. European Journal of Operational Research, 251(3), 918-929. https://doi.org/10.1016/j.ejor.2015.11.016

Lumbroso, D., \& Vinet, F. (2012). Tools to improve the production of emergency plans for floods: are they being used by the people that need them? Journal of Contingencies and Crisis Management, 20(3), 149-165.

https://doi.org/10.1111/j.1468-5973.2012.00665.x

Lyu, H., Sun, W., Shen, S., \& Zhou, A. (2020). Risk assessment using a new consulting process in fuzzy AHP. Journal of Construction Engineering and Management, 146(3), 04019112. https://doi.org/10.1061/(ASCE)CO.1943-7862.0001757

Masoum, M. A. S., \& Fuchs, E. F. (2015). Power quality in power systems and electrical machines. Academic Press.

Medasani, S., Kim, J., \& Krishnapuram, R. (1998). An overview of membership function generation techniques for pattern recognition. International Journal of Approximate Reasoning, 19(3-4), 391-417.

https://doi.org/10.1016/S0888-613X(98)10017-8

Megahed, S. M., \& Hassan, M. F. (2000, February 15-17). Current advances in mechanical design and production Vii: proceedings of the Seventh Cairo University International Mdp Conference. Cairo-Egypt. Pergamon.

Mello, A. S., \& Ruckes, M. E. (2006). Team Composition. The Journal of Business, 79(3), 1019-1039. https://doi.org/10.1086/500668

Mianabadi, H., \& Afshar, A. (2008). A new method to evaluate weights of decision makers and its application in water resource management. In Proceedings of the 13th IWRA World Water Congress, Montpelier, France (pp. 1-10).

Moynihan, D. P. (2009). The network governance of crisis response: case studies of incident command systems. Journal of Public Administration Research and Theory, 19(4), 895-915. https://doi.org/10.1093/jopart/mun033

Nahmias, S. (1978). Fuzzy variables. Fuzzy Sets and Systems, 1(2), 97-110. https://doi.org/10.1016/0165-0114(78)90011-8

Nokhbatolfoghahaayee, H., Menhaj, M. B., \& Shafiee, M. (2010). Fuzzy decision support system for crisis management with a new structure for decision making. Expert Systems with Applications, 37(5), 3545-3552.

https://doi.org/10.1016/j.eswa.2009.10.011

Nowlis, S. M., Kahn, B. E., \& Dhar, R. (2002). Coping with ambivalence: the effect of removing a neutral option on consumer attitude and preference judgments. Journal of Consumer Research, 29(3), 319-334. https://doi.org/10.1086/344431
Pamučar, D., Stević, Ž., \& Sremac, S. (2018). A new model for determining weight coefficients of criteria in MCDM Models: Full Consistency Method (FUCOM). Symmetry, 10(9), 393. https://doi.org/10.3390/sym10090393

Ryjov, A. (2003). Fuzzy linguistic scales: definition, properties and applications. In Soft Computing in Measurement and Information Acquisition, 23-38. Springer. https://doi.org/10.1007/978-3-540-36216-6_3

Rosenthal, U., 't Hart, P., \& Kouzmin, A. (1989). Coping with crises: the management of disasters, riots and terrorism. Australian Journal of Management, 16(1), 99-102.

https://doi.org/10.1177/031289629101600108

Rosenthal, U., Hart, P. t., \& Kouzmin, A. (1991). The bureaupolitics of crisis management. National Emergency Training Center. https://doi.org/10.1111/j.1467-9299.1991.tb00791.x

Saaty, T. L. (1977). A scaling method for priorities in hierarchical structures. Journal of Mathematical Psychology, 15(3), 234281. https://doi.org/10.1016/0022-2496(77)90033-5

Saaty, T. L. (1980). The analytic hierarchy process. McGraw-Hill. https://doi.org/10.21236/ADA214804

Saaty, T. L. (1990). How to make a decision: The analytic hierarchy process. European Journal of Operational Research, 48(1), 9-26. https://doi.org/10.1016/0377-2217(90)90057-I

Saaty, T. L., \&Vargas, L. (1994). Fundamentals of decision making and priority theory with the analytic hierarchy process. RWS.

Sechilariu, M., \& Locment, F. (2016). Urban Dc microgrid: intelligent control and power flow optimization. ButterworthHeinemann.

Shallit, J. (2009). Hamming distance for conjugates. Discrete Mathematics, 309(12), 4197-4199. https://doi.org/10.1016/j.disc.2008.11.001

Užga-Rebrovs, O., \& Kuḷešova, G. (2017). Comparative analysis of fuzzy set defuzzification methods in the context of ecological risk assessment. Information Technology and Management Science, 20(1), 25-29. https://doi.org/10.1515/itms-2017-0004

Voskoglou, M. G. (2018). Application of fuzzy relation equations to student assessment. American Journal of Applied Mathematics and Statistics, 6(2), 67-71. https://doi.org/10.12691/ajams-6-2-5

Wang, G. A., Jiao, J., Abrahams, A. S., Fan, W., \& Zhang, Z. (2013). ExpertRank: A topic-aware expert finding algorithm for online knowledge communities. Decision Support Systems, 54(3), 1442-1451. https://doi.org/10.1016/j.dss.2012.12.020

Wang, Y.-M., Yang, J.-B., Xu, D.-L., \& Chin, K.-S. (2006). On the centroids of fuzzy numbers. Fuzzy Sets and Systems, 157(7), 919-926. https://doi.org/10.1016/j.fss.2005.11.006

$\mathrm{Xu}, \mathrm{Z}$. (2012). Linguistic decision making: Theory and methods. Springer. https://doi.org/10.1007/978-3-642-29440-2

Yu, C.-S. (2002). A GP-AHP method for solving group decisionmaking fuzzy AHP problems. Computers \& Operations Research, 29(14), 1969-2001. https://doi.org/10.1016/S0305-0548(01)00068-5

Zadeh, L. A. (1965). Fuzzy sets. Information and Control, 8(3), 338-353. https://doi.org/10.1016/S0019-9958(65)90241-X

Zhang, R., Phillis, Y. A., \& Kouikoglou, V. S. (2005). Fuzzy control of queuing systems. Springer.

Zhu, F., Zhong, P.-A., \& Sun, Y. (2018). Multi-criteria group decision making under uncertainty: Application in reservoir flood control operation. Environmental Modelling \& Software, 100, 236-251. https://doi.org/10.1016/j.envsoft.2017.11.032 